\title{
Percepções de Adolescentes acerca de seus Encontros Familiares ${ }^{1}$
}

\author{
Rosana Maria Freitas de Lemos $^{2}$ \\ Lorena Ribeiro dos Santos ${ }^{3}$ \\ Fernando Augusto Ramos Pontes ${ }^{4}$ \\ Universidade Federal do Pará
}

\begin{abstract}
RESUMO - Este trabalho investigou de forma exploratória a percepção de adolescentes dos seus encontros familiares. Para tanto, utilizou-se uma metodologia qualitativa denominada grupo focal. Participaram da pesquisa 11 adolescentes, entre 12 e 15 anos, pertencentes a uma população de baixa renda da cidade de Belém. O ambiente selecionado foi uma creche pública. O procedimento da pesquisa foi dividido em cinco etapas: seleção dos participantes, apreciação do conselho de ética em pesquisa, obtenção do consentimento dos pais, realização da técnica do grupo focal e análise dos dados. Os resultados da pesquisa demonstraram que a união, o senso de pertencimento ao grupo familiar, o clima emocional de alegria, o compartilhamento de experiências, a troca emocional de sentimentos positivos e a ausência de conflitos contribuem para que os adolescentes percebam os encontros de família como uma experiência satisfatória.
\end{abstract}

Palavras-chave: encontros familiares; adolescência; percepção; satisfação.

\section{Adolescent's Perceptions concerning their Family Meetings}

\begin{abstract}
This work investigated, in an exploratory way, the adolescents' perception of their family meetings. It was applied a qualitative methodology called focal group. Eleven adolescents, from 12 to 15 years old, of low-income population in the city of Belém, participated in this research. The place chosen was a public day care. The research procedure was divided in five steps: participants' selection, appreciation of the research ethic committee, collection of parents' permission, application of the focal group technique, and data analysis. The results indicated that the union, the sense of belonging to the family group, the happiness perceived in the environment, the sharing of experiences, the exchange of positive feelings and the absence of conflicts contribute to the adolescents` perceptions of family meetings as a satisfactory experience.
\end{abstract}

Keywords: family meetings; adolescence; perception; satisfaction.

A família é considerada o mais forte pilar da existência humana, pois é a primeira fonte de socialização, sendo nesse contexto que se inicia grande parte das relações interpessoais. Sendo assim, a família exerce um forte poder sobre o comportamento humano. Há características familiares específicas que pressupõem um maior envolvimento entre seus membros, como os encontros de família que podem ser formais ou informais e associados a eventos especiais ou a situações simples do dia-a-dia como as refeições. Os encontros de família podem ser considerados fatores importantes no fortalecimento dos relacionamentos e na troca emocional, proporcionando contatos e oportunidades para criar momentos considerados especiais pela família (Fiese, 2002).

Desta forma, com o despertar do interesse nos encontros familiares, iniciou-se na área da Psicologia da Família, mais

1 Este trabalho foi baseado na dissertação de mestrado da primeira autora apresentada em 2005 ao Programa de Pós-Graduação em Teoria e Pesquisa do Comportamento/UFPA, sob a orientação do terceiro autor.

2 Durante a realização do trabalho foi bolsista do CNPq. Endereço para correspondência: Rua João Balbi, 1099, Ap. 1401. Belém, PA. CEP 66060-280.E-mail: rosanasomel@hotmail.com.

3 Bolsista de IC do CNPq.

4 Pesquisador II do CNPq. especificamente na abordagem sistêmica, o estudo dos encontros familiares e de seus impactos desenvolvimentais.

Eisenberg, Olson, Story e Bearinger (2004) salientam que os encontros de família correspondem a um elemento chave para o desenvolvimento saudável dos adolescentes e acrescentam, ainda, que realizar as refeições conjuntamente pode ser um meio de fornecer oportunidades de socialização, de desenvolvimento da habilidade comunicativa, assim como de aprendizagem de boas maneiras e bons hábitos alimentares. Interessados nesses aspectos, os autores conduziram uma pesquisa com o objetivo de descobrir a relação entre a freqüência da realização de refeições com a família reunida e os indicadores de saúde e bem-estar dos adolescentes referentes ao fumo, ao uso de drogas, ao desempenho acadêmico, à auto-estima e ao envolvimento com tentativas de suicídio.

Para tal, Eisenberg e cols. (2004) solicitaram a 4. 746 adolescentes, pertencentes a diferentes raças e classes sócioeconômicas, que respondessem a uma escala de quatro itens para medir a coesão familiar. Dentre os aspectos que foram analisados encontravam-se a frequência de reuniões familiares, a segurança do amor dos pais e o grau de confiança nos pais. Os adolescentes responderam, ainda, a um questionário relacionado ao desempenho acadêmico e ao uso de substâncias como álcool, cigarro e maconha. E, finalmente, preencheram uma escala para medir a autoestima, que foi 
adaptada a partir do questionário de Auto-Estima de Rosenberg (Rosenberg, 1965). Os resultados indicaram que a alta frequência de refeições familiares estava associada a uma taxa significativamente reduzida das seguintes variáveis: uso de maconha, cigarro e álcool; idealização suicida; graves sintomas depressivos e baixa auto-estima.

Kumpfer (2002) aponta que os fatores familiares positivos, como bons relacionamentos, comunicação dos valores e das expectativas dos pais aos filhos, supervisão e métodos positivos de disciplina contribuem para que os jovens não se engajem em comportamentos delinquentes. Por outro lado, a ausência de diálogo e de oportunidades para reforçar as alianças entre pais e filhos, o desinteresse ou a falta de tempo dos pais para compartilhar experiências, assim como a carência de apoio com relação aos sonhos, projetos e objetivos de vida dos filhos, podem ser fatores associados à aquisição de problemas desenvolvimentais.

Sendo assim, os pesquisadores Fiese (1992), Kumpfer (2002), Eaker, Walters e Lynda (2002) e Eisenberg e cols. (2004) concordam que os relacionamentos familiares influenciam de forma significativa o comportamento de seus membros, servindo inclusive de fatores de proteção potenciais na vida dos adolescentes por trazer benefícios que vão além da coesão familiar, como a prevenção de comportamentos antissociais.

Levando em consideração esses aspectos, a presente pesquisa buscou analisar a percepção de adolescentes sobre seus encontros de família e relacioná-la com a sua satisfação. Acredita-se que esta análise pode revelar aspectos que podem favorecer a criação de uma relação mais próxima e prazerosa dos adolescentes com sua família.

As hipóteses alternativas da pesquisa são as seguintes: (1) há determinadas percepções quanto aos encontros de família que podem satisfazer os adolescentes contribuindo para que estes tenham mais interesse de participar dessas reuniões e de se aproximar da família; (2) certas percepções dos encontros de família podem exercer impacto sobre a personalidade dos adolescentes.

Vale ressaltar que para alcançar os objetivos propostos foi necessário optar-se por um enfoque qualitativo de investigação e tratamento dos dados, uma vez que somente dessa forma seria possível a obtenção de informações pormenorizadas acerca das experiências de vida dos participantes em seus encontros de família. Para tanto, utilizou-se a técnica denominada grupo focal.

Segundo Iervolino e Perlicione (2001), essa técnica funciona da seguinte forma. O moderador guia grupos, de aproximadamente 10 pessoas, numa discussão que tem por objetivo revelar experiências, sentimentos, percepções e preferências dos participantes. Os grupos são formados por participantes que têm características em comum e são incentivados pelo moderador a conversarem entre si, trocando experiências e interagindo sobre suas idéias, sentimentos, valores e dificuldades. O papel do moderador é promover a participação de todos, impedir a dispersão dos objetivos da discussão e a monopolização de alguns participantes sobre outros. $\mathrm{O}$ assunto é identificado num roteiro de discussão e são selecionadas técnicas de investigação para a coleta das informações, como a análise de discurso.
Quadro 1. Perfil dos participantes do grupo focal.

\begin{tabular}{ccll}
\hline Sexo & $\mathbf{N}^{\mathbf{0}}$ & Nível de Ensino & Código \\
\hline F & 1 & Ensino Fundamental- EF & F1EF \\
F & 2 & Ensino Fundamental- EF & F2EF \\
M & 3 & Ensino Fundamental- EF & M3EF \\
F & 4 & Ensino Médio- EM & F4EM \\
F & 5 & Ensino Fundamental- EF & F5EF \\
M & 6 & Ensino Médio- EM & M6EM \\
M & 7 & Ensino Fundamental- EF & M7EF \\
F & 8 & Ensino Fundamental- EF & F8EF \\
F & 9 & Ensino Fundamental- EF & F9EF \\
F & 10 & Ensino Fundamental- EF & F10EF \\
F & 11 & Ensino Fundamental- EF & F11EF \\
\hline
\end{tabular}

\section{Método}

\section{Participantes}

Fizeram parte do estudo 11 adolescentes pertencentes a uma população de baixa renda, sendo oito do sexo feminino e três do sexo masculino, na faixa etária entre 12 e 15 anos. Essa faixa etária foi escolhida por apresentar mais características em comum no que se refere à rotina, em comparação com os demais adolescentes de outras faixas etárias, permitindo assim, uma maior padronização da população. Na época da coleta de dados, os participantes cursavam o Ensino Fundamental (EF) ou o Ensino Médio (EM) em escolas públicas da região da periferia da cidade de Belém, sendo nove participantes do EF e dois do EM

O Quadro 1 identifica os participantes selecionados no grupo focal. Ressalta-se que cada participante recebeu um código que se referia, respectivamente, ao sexo, ao número de identificação e ao nível de ensino em que se encontrava.

\section{Ambiente}

A coleta de dados foi realizada em uma creche que realiza trabalhos sociais com adolescentes, além de crianças, e assim, possuía cadastros dos adolescentes que residiam nas proximidades.

\section{Procedimento}

Passo 1: Seleção dos adolescentes que apresentavam um perfil semelhante quanto aos dados sociodemográficos e de rotina diária. $\mathrm{O}$ primeiro se refere à baixa renda e a residir na mesma localização, e o segundo está relacionado a frequentar escola pública e não trabalhar. Esses quesitos foram verificados a partir dos cadastros de adolescentes que a creche dispunha; 
Passo 2: Apreciação do projeto pelo Conselho de Ética em Pesquisa e envio do Termo de Consentimento Livre e Esclarecido aos pais;

Passo 3: Realização da técnica de grupo focal, a qual se deu em três encontros com a presença dos 11 adolescentes. Suas verbalizações foram gravadas por meio de um gravador de áudio. A técnica de grupo focal, com seu respectivo guia temático, foi pré-testada em estudo piloto realizado com 12 adolescentes que não fizeram parte da amostra aqui considerada;

Passo 4: Digitação e posterior análise das verbalizações dos adolescentes.

\section{Análise dos dados}

A análise do material coletado foi feita com base na análise dos discursos dos participantes. A análise foi dividida em duas etapas. Na primeira etapa, os dados foram agrupados e organizados em temas com o objetivo de formar uma categoria qualitativa, tomando como base a relevância das informações prestadas. Na segunda etapa, tendo como referência a formulação da categoria qualitativa, iniciou-se a análise dos discursos que se compatibilizavam com esta, visando corroborar os dados existentes na literatura e/ou verificar novos fenômenos emergentes para realização de análises e interpretações.

\section{Resultados e Discussão}

Em função da necessidade de uma análise focal, deu-se ênfase na discussão relacionada à "percepção dos encontros de família e sua relação com a satisfação dos membros", uma vez que a análise de outros fatores poderia ser demasiadamente extensa e fugiria dos parâmetros do presente estudo.

A partir dos relatos pode-se notar que os encontros de família são percebidos diferentemente de acordo com a experiência de cada um dos adolescentes nos eventos. Os fatores que contribuem para essas percepções são apontados ao longo dos trechos.

A presença deles é importante (...), me sinto importante com eles, porque eu gosto deles e eles gostam de mim (F1EF)

(...) a gente brinca, eu me divirto, brinco com os meus irmãos, com minhas primas e ai eu acho especial porque eu estou com eles... (F2EF)

(...) o encontro familiar é legal, a gente conversa, bate papo, come... (M3EF)

(...) tem uns tios meus, principalmente tias, bebem bastante, não sabem beber, ai acabam brigando, ai um quer dar garrafada no outro (F4EM)

Eu gosto dos meus parentes, gosto muito, a gente conversa bastante, principalmente com as minhas tias, gosto de conversar muito com elas, elas vão em casa, conversam muito com a minha mãe, com meus irmãos, a gente sai e é muito bom!... eu gosto de ficar reunida com a minha família, batendo papo, conversando sobre as coisas, estudo, sobre o futuro..

(F5EF)

(...) é muito animado, todo mundo tá conversando sempre, dá pra eu interagir nas conversas (...) e não tem aquela rixa de família, tipo pai não vai com a cara do tio, tio não vai com a cara da mãe. Todo mundo se dá bem na hora, naquela hora é um momento especial pra família, tá todo mundo unido ali ... (M6EM)

(...) eu acho que as pessoas precisam uma das outras, por exemplo, um filho precisa do amor da mãe, um irmão precisa do amor do outro irmão, do pai e assim por diante... (M7EF)

Eu acho mais ou menos, porque a maioria das minhas tias gosta de levar os sobrinhos, isto é muito chato. Só é bebida, não suporto bebida. Não tem ninguém da minha idade. Sinto mais ou menos união da família porque o outro diz: ela (mãe) tá muito velha pra fazer aniversário, eu vou embora, ai eles vão embora e fica só a metade da família, alguns são chatos. (...) os parentes são muito falsos, quando eles entram na casa eles reparam logo, ah tem uma teia de aranha, quando eles vão embora eles ficam falando mal (F8EF)

Eu não gosto não me dou muito com esse negócio de reunião de família, não dou muito valor nisto. Eu preferia não ir porque chega lá, a gente só vai ficar olhando pra cara dos outros, eles vão ficar conversando lá sobre assuntos de adulto, eles falam que a gente é criança, que não pode participar da conversa deles e ai fica chato (F9EF)

O lado ruim é que eles se sentem inferiores, se sentem diferentes, ai a mamãe vai ficar lá na frente, brinca e conversa, e a mamãe vai embora, eles falam para as outras pessoas que a mamãe é diferente, é melhor, que ganha mais, que tem a casa mais bonita. Esse é o lado ruim dos encontros (F10EF)

Os encontros de família são muito chatos, porque a maioria das tias gostam de estar criticando, se a gente usa uma saia e ai já ficam falando, é isso e aquilo, eu acho muito chato isso. Eu não gosto de reunião de família, é muito chato (F11EF)

Os adolescentes que vivenciam uma experiência positiva nos encontros de família ressaltaram alguns fatores específicos que contribuem para essa percepção, tais como o clima emocional de alegria, a união entre os membros da família, a conversa entre eles e entre os membros adultos, o compartilhamento da refeição, a segurança de que há reciprocidade na troca emocional de sentimentos positivos e a ausência de conflitos. Outro aspecto que pode ser salientado é o fato de que quando a participação deles é incentivada pelo grupo familiar, abre-se um espaço para que eles ocupem um papel central nos encontros, oportunizando uma participação ativa. Esses fatores proporcionam a criação do sentimento de satisfação e de pertencimento ao grupo, assim como favorece a auto-estima.

Deve-se salientar, entre esses fatores, que a possibilidade de interagir e participar das conversas com os membros adultos é apontado como um fator positivo do ponto de vista dos 
adolescentes, principalmente levando em consideração o fato de que alguns referem tentar participar, mas são excluídos. E, finalmente, a possibilidade de se divertir e brincar livremente com os membros da família da mesma faixa etária é também um indicativo de satisfação.

Todos esses aspectos evidenciados podem sugerir a criação de uma nova categoria de encontro de família a qual se denomina aqui de encontro familiar intenso, já que possui como principais características a alegria, a satisfação e o envolvimento emocional.

Por outro lado, alguns relatos revelam também as insatisfações vivenciadas por alguns adolescentes e apontam os motivos dessas insatisfações. Um dos pontos principais é a exclusão no que se refere à participação nas reuniões: o papel ocupado pelo adolescente é de simples expectador, sendo-lhe negado o direito a uma participação ativa frente aos seus familiares adultos. Esse resultado corrobora a teoria de Oswald (2002) que afirma que os encontros familiares podem também excluir parcial ou totalmente os membros da família.

Outro fator relatado e associado à insatisfação com os encontros de família é a presença de críticas. A tentativa de controle do comportamento por parte dos membros da família extensa é visto como algo negativo que pode provocar o afastamento dos adolescentes dos rituais. Talvez isso ocorra porque as críticas são uma forma de expressar a inadequação, levando o adolescente a se sentir incomodado e a questionar seu grau de aceitação frente a seus familiares. Além disso, a bebida por parte dos adultos é indicada como causadora de grande insatisfação. Os adolescentes referem que a bebida contribui para a ocorrência de brigas entre os membros, provocando um clima negativo no evento. Isso pode ser prejudicial aos adolescentes, uma vez que a família representa um modelo comportamental para os filhos (Wolin \& Bennet, 1984). Tais acontecimentos podem minimizar a probabilidade do adolescente vir a desenvolver o senso de união.

Finalmente, a presença de crianças, a falta de pessoas da mesma idade e a "falsidade" dos parentes ao falar mal das pessoas envolvidas no evento são indicados como fatores que podem afetar a sensação de bem-estar nos encontros de família.

Pode-se dizer que os fatores colocados tantos nos aspectos positivos como negativos têm dois aspectos em comum: de um lado, o sentimento de união, de ser parte, de estar incluído, o que vai ao encontro de Fiese (2002) que refere que os encontros familiares favorecem a criação do senso de pertencimento ao grupo. De um outro lado, está o sentimento de desunião, de estar à parte, de estar excluído, o que está de acordo com Oswald (2002) que afirma que os encontros familiares podem também excluir parcial ou totalmente os membros da família.

\section{Considerações Finais}

Este trabalho constitui-se em uma aproximação exploratória da temática dos encontros de família a partir da noção implícita e justificada na literatura consultada quanto à relevância de pesquisar tais assuntos.
Sendo assim, a partir deste estudo tornou-se possível verificar alguns aspectos, tais como a tipologia dos encontros familiares, uma vez que as evidências obtidas sugerem a criação de uma nova categoria, a qual se denomina aqui de "encontros familiares intensos". Entende-se que essa categoria possui duas características: percepção positiva do encontro familiar que gera, por sua vez, satisfação de todos os membros da família, independentemente das gerações as quais pertencem, e um forte envolvimento emocional.

O desenvolvimento dessa categoria acrescenta um elemento novo à análise dos encontros de família, pois considera os fatores que levam os membros familiares a perceberem os encontros familiares como satisfatórios e, conseqüentemente, contribui não apenas para que os adolescentes participem com maior frequência desses encontros, mas como também gera um maior envolvimento emocional entre os membros.

Além disso, os dados levantados no grupo focal apontaram que o sentimento de pertencimento ao grupo que ocorre quando os participantes percebem que estão efetivamente incluídos e ativos no encontro, é uma das características centrais que favorece a satisfação nos encontros familiares. No entanto, a ausência do sentimento de pertencimento ao grupo pode estar associada com o afastamento dos adolescentes não só das reuniões de família quanto também dos próprios membros da família.

Desse modo, nem sempre uma percepção positiva de alguns entes indica que os outros também percebam da mesma forma, podendo haver diferentes percepções quanto a esse aspecto. Isto freqüentemente ocorre quando alguns membros conversam, divertem-se, mas não permitem que outros tenham o direito a uma participação ativa, restando a eles exercerem papéis de meros coadjuvantes, não sendo sequer permitido sua participação nas conversas, como é o caso de alguns adolescentes pesquisados.

Enfim, esta pesquisa procurou mostrar como se dá a percepção dos encontros de família na visão dos adolescentes e fez algumas relações entre a percepção e a satisfação vivenciada por eles nessas reuniões. Estudos futuros poderiam investigar outros aspectos relacionados ao tema, como a transmissão de valores, as características do evento, os fatores causadores de satisfação ou insatisfação aos membros da família, os sentimentos envolvidos etc. Acredita-se que essas informações possam trazer contribuições relevantes quanto ao referencial teórico acerca do tema em questão.

\section{Referências}

Eaker, D., Walters, H., \& Lynda, H. (2002). Adolescent satisfaction in family rituals and psychosocial development: A developmental system theory perspective. Journal of Family Psychology, 16, 406-414.

Eisenberg, M., Olson, R., Story, M., \& Bearinger, L. (2004). Correlations between family meals and psychosocial wellbeing among adolescents. Arquives of Pediatric \& Adolescent Medicine, 158, 792-796.

Fiese, B. H. (1992). Dimensions of family rituals across two generations: Relation to adolescent identity. Family Process, 31, 151-162. 
Fiese, B. H. (2002). Routines of daily living and rituals in family life: A glipse at stability and change during the early child-raising years. National Institute of Mental Health, 14, 10-13.

Iervolino, S. A., \& Pelicione, M. C. F. (2001). A utilização do grupo focal como metodologia qualitativa na promoção da saúde. Revista da Escola de Enfermagem USP, 35, 115-121.

Kumpfer, C. (2002). Family-strengthening approaches for the prevention of youth problem behavior. Journal of Adolescent Research, 16, 444-448.

Rosenberg M. (1965). Society and the adolescent self image. Princeton, NJ: Princeton University Press.
Oswald, R. F. (2002). Inclusion and belonging in the family rituals of gay and lesbian people. Journal of Family Psychology, 16, 428-436.

Wolin, S. J., \& Bennet, L. A. (1984). Family rituals. Family Process, 23, 401-420.

Recebido em 08.02.07 Primeira decisão editorial em 07.06.07 Versão final em 05.07.07 Aceito em 21.02.08 